\title{
Complex adaptive systems as metaphors for organizational management
}

\author{
Klara Palmberg \\ Luleå University of Technology, Luleå, Sweden
}

\section{Complex adaptive systems}

\begin{abstract}
Purpose - The purpose of this paper is to explore the concept of complex adaptive systems (CAS) from the perspective of managing organizations, to describe and explore the management principles in a case study of an organization with unconventional ways of management and to present a tentative model for managing organizations as CAS - system management. There is a need for the development of knowledge, metaphors and language for management of the new forms of organizing, for example, value networks, which are evolving as a response to the increased demand for efficiency, flexibility and innovation.
\end{abstract}

Design/methodology/approach - The frame of reference is based on a literature review of the area of CAS and an inductive and interactive approach is used to identify the management principles in the case study.

Findings - A classification of the components of a CAS is suggested and described as properties of, and approaches for, managing CAS. The identified management principles in the case study are: a clearly formulated mission, delegation of responsibility and authority, diversity and competition, and follow-up and feedback. As a result of analyzing the frame of reference and the case study, a tentative, conceptual model for managing organizations as CAS - system management - is presented including; metaphor, components and approaches.

Originality/value - The case study contributes to the empirical body of knowledge of organizing and management. The tentative model is a contribution to the ongoing discussion about managing organizations as CAS.

Keywords Adaptive systems theory, Network synthesis, Chaos theory, Complexity theory, Case studies, Metaphors

Paper type Research paper

\section{Introduction - challenges for the organizations of this century}

During the twentieth century the development of production technology fundamentally influenced the society and the logic of business and organizations. In a similar way, the shift to the twenty-first century has been dominated by the development of information technology, affecting the way we communicate and the conditions for organizations, business and the production of goods and services. The consequences of the development of information technology include: increased interconnectedness, transparency, empowerment of individuals, speed of transactions, and decreased cost of information. These trends require organizations that can combine efficiency with flexibility and innovation (Cohen, 1999; Hamel, 2007; Sandberg and Targama, 2007).

To respond to the demand for flexibility organization forms are emerging that are assembled at short notice, for a limited period of time and a limited purpose, and then disbanded (Cohen, 1999). Products and services are produced in new constellations, in networks of actors. The ability to use both external and internal resources to solve tasks has become more common. Organizations are increasingly involved in these

483 
TLO

16,6

484

value networks or business ecosystems of which they have only limited control (Hamel, 2007). In this paper, the term organization includes the whole span from traditional companies to loosely connected networks of actors temporarily working together.

One of the challenges is to hand over significant control to people outside the company. The new organization forms challenge the role of management, the value of experts, the need for control over the customer experience and the importance of quality assurance (Cook, 2008; Tapscott and Williams, 2006).

Even though the organization forms are evolving, many of the existing principles for management have not changed significantly (Hamel, 2007, 2009). The principles of modern management, resting on the foundations of Fayol, Taylor and Weber, could be described as: stability as the objective, analysis by reduction to parts, and cause and effect mechanisms between the parts.

Almost 20 years ago, Senge (1990) described how managers have a language designed for simple, static problems at hand when facing the challenges of the current business environment of complex, dynamic realities. Still, the dominating metaphor of an organization is the hierarchical organization.

Morgan (2006, p. 4) argues that the use of metaphors implies a way of thinking and a way of understanding the world. There is a lack of metaphors for organizational forms such as value networks, mass collaboration, multiunit enterprises, and user contribution systems.

\subsection{Complexity - possible metaphor for organizations?}

Earlier analysis of organizations succeeding in implementing process management shows that functional and process structures co-exist, creating a dynamic matrix in the organization, see Palmberg (2009a, b). Organizational complexity is increased rather than reduced in order to handle several parallel perspectives on the business. One can also argue that the development of increased interconnectedness, transparency, empowerment of individuals, speed of transactions, and decreased cost of information also contributes to the challenge of complexity.

How to manage complexity instead of reducing it is a challenge for the management of contemporary organizations. There are several authors arguing for the possibilities of applying ideas of complex adaptive systems (CAS) to managing organizations (Lissack, 1999). A CAS is defined as a set of interdependent agents forming an integrated whole, where an agent may be a person or an organization.

An example of an organization where several of the properties of CAS described in the literature are visible has been identified. The education system of Nacka municipality, Sweden, displays several seemingly unconventional ways of management. At the same time Nacka has received several instances of national recognition for their results.

As described above, there is a need for development of metaphors and language for managing of the new forms of organizing that are evolving. As an attempt to approach this challenge, the purpose of this paper is threefold:

(1) To explore the concept of CAS from the perspective of managing organizations.

(2) To describe and explore the management principles of the education system of Nacka municipality - a case study of an organization with unconventional ways of management.

(3) To present a tentative model of metaphors and approaches for managing organizations as CAS - system management. 
2. Frame of reference - complex adaptive systems

Concepts that deal with complex adaptive systems (CAS) have many names: chaos theory (Tetenbaum, 1998), complexity theory (Smith, 2005), complexity science (Kelly and Allison, 1999; Stacey, 2003) and systems thinking (Senge, 1990). Ackoff (1999) argues that the general systems theory of von Bertalanffy (1968) where major stimuli for the awareness of the nature of systems and the implications of their nature for effective organizations and management.

In the following sections, two classifications are suggested for the components of CAS:

(1) properties of CAS (see the left side of Figure 1); and

(2) approaches for managing CAS (see the right side of Figure 1).

The elements of each, i.e. the properties and approaches, will be presented. A more thorough description can be found in Palmberg (2009c).

\subsection{Properties of complex adaptive systems}

According to Zimmerman et al. (1998), a system is a set of connected or interdependent agents, where an agent may be an organization, department, team or a person. Between the agents of a CAS exist dynamic, varying and non-linear connections and interactions (Augustinsson, 2006; Ng, 2009).

Organizations act and react in cooperation and in competition with other agents (co-evolution). Therefore, a CAS can only be understood in the context of its environment. It is by contemplating the whole, and the relationships and interactions between agents, that one understands a system: not by the absolute knowledge about each agent (Senge, 1990; Zimmerman et al., 1998; Richardson, 2008).

When analyzed, CAS are not predictable in detail, because of their interdependencies and non-linearity. However, it is still possible to find inherent order in the complex systems. Senge (1990, p. 290) makes the case that "The art of systems thinking lies in seeing through complexity to the underlying structures generating change."
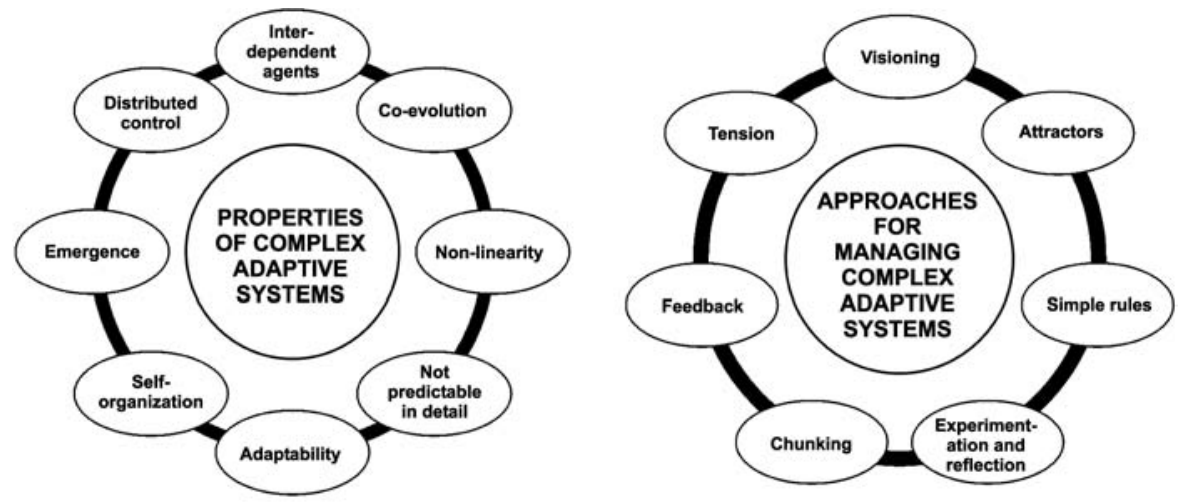

Source: Assembled by the author
Complex adaptive systems

485 
TLO

16,6

486
CAS are seen as adaptable, which means that they have the ability to learn from their own experience and adapt to new, unexpected conditions (Zimmerman et al., 1998). Richardson (2008) defines the autonomy of each agent as the local memory of the agent and the ability to learn from his or her experience and to generate new responses.

Interdependent agents acting together will unwittingly create something new by self-organizing. For self-organization to take place, it takes a state of bounded instability; this state is often described as "the edge of chaos" (Kelly and Allison, 1999). Organizations use their cultural codes in the same way as biological systems use genetic codes to self-organize (Gharajedaghi, 1999).

Emergence is a property of a CAS that comes out of the interaction of many participants (agents) (Gharajedaghi, 1999; Lissack, 1999). Richardson (2008) states that emergence is often portrayed as a process whereby the properties of the whole emerge from the properties of the parts.

The property of distributed control is opposite to a hierarchical central authority, which directs all agents (Zimmerman et al., 1998). Senge (1990) calls this property localness.

\subsection{Approaches for management of complex adaptive systems}

A number of authors strongly argue that CAS cannot be controlled: see Cilliers (2000) cited in Augustinsson (2006) and Stacey (2003). According to Tapscott and Williams (2006), even though a CAS cannot be controlled, as is assumed in the approach of the traditional management of hierarchical organizations, a CAS can be managed. Deming (1994) states that a system must be managed, and that it is the job of the management to direct the efforts of all the components towards the goals of the system. A number of approaches for this will be presented below.

If any one idea about leadership has inspired organizations, it is the capacity to hold a shared picture of the future we seek to create - visioning (Senge, 1990). Another suggested approach is to use attractors (Gharajedaghi, 2007). It is argued that there is no such thing as resistance - there is only attraction. To change something, all one has to do is create stronger attractors than the ones in place. The basic idea is to leave behind the principle of managing through detailed instructions, which decreases the freedom of the individual agent, and, instead, to lead by making people embrace visions, creating attractors and stimulating individual agents and organizations to use their inherited abilities (Sandberg and Targama, 2007).

In 1986, Craig Reynolds was trying to program a computer simulation of a flock of birds. With the available computer capacity, it was difficult to make the calculations, since the birds expressed such complex behavior when flying. Instead, he created a simulation of autonomous agents (boids) whose behaviors were governed only by three rules (steering behaviors), which steer how an individual boid maneuvers, based on the positions and velocities of its nearby flock mates (Reynolds, 2001). His three rules were:

(1) Separation - steer to avoid crowding local flock mates.

(2) Alignment - steer towards the average heading of local flock mates.

(3) Cohesion - steer to move toward the average position of local flock mates.

The remarkable thing was that, governed by these three simple rules, the flocks of boids could handle varying environments, which were filled with obstacles, without being controlled or steered: 
... it does show that simple rules [...] can lead to complex behaviors. These complex

behaviors emerge from the interactions among agents, rather than being imposed upon the

CAS by an outside agent or explicit, detailed description. (Zimmerman et al., 1998, p. 26)

\section{Complex adaptive systems}

While the traditional approach to problem solving is to start with an extensive analysis of the problem, the approach when managing CAS is to experiment. To take an issue that is overwhelmingly complex and start with small, simple experiments. Perform the experiments and reflect carefully. Adopt the good parts by dropping what clearly will not work and continue by linking the pieces that work together (chunking), and allow the solution to emerge.

Feedback is the action of feeding or reporting back the results of an action to the people performing that action (Kelly and Allison, 1999). According to Eurat (2006), feedback is accepted as a key factor affecting learning, cited in Augustinsson (2006). It is the concept of feedback that allows for emergence, self-organization, adaptability and learning in CAS (Richardson, 2008).

Just because the approach of simple rules is suggested above, it does not mean that everything should be simplified: in fact, just the opposite is required. Traditionally, in the industrial era, stability was a success factor among organizations. Today, with the pressure to remain innovative and flexible, managers instead need to create an environment of tension and instability. It is a challenge for managers to keep the tension level where it generates dynamic imagination without exceeding people's ability to handle the stress engendered (Tetenbaum, 1998). One approach to creating tension is to ensure that the organization is diverse (Zimmerman et al., 1998).

\section{Research approach}

The business environment keeps changing and there is an increased need for researchers to interact with organizations and managers to develop new knowledge on management. Sandberg and Targama (2007) make the point that the development of our society stresses the need for understanding. Weiss $(1977,1980,1986)$ describes the conceptualizing function and purpose of research as contributing with concepts, ideas, understanding and insights that can have an impact on how we relate and affect our standpoints.

The use of case studies is becoming an increasingly important approach because of its ability to investigate little-known and complex phenomena such as organizations (Gummesson, 2000, 2007, 2008). Lee et al. (2007) argue that empirically based case studies have the potential to contribute to the development of both theory and practice. The case study approach used is further described in Palmberg (2009d).

\subsection{Purposeful selection}

Earlier studies of process management, both in organizational settings and in the literature, have shown that process management does not seem to be the full answer to how contemporary organizations should manage and organize their business (Palmberg, 2009a, b). For this case study, an organization has been identified where process management is considered as necessary, but not sufficient. As a complement, several of the properties of CAS described in the literature are visible. The education system of Nacka municipality displays several seemingly unconventional ways of management, while at the same time receiving several instances of national recognition of their results. 
TLO

16,6

488
Altogether, Nacka is a successful system with behavior and management principles that seem different from organizations studied earlier. Kalleberg (1993) categorizes this as varied research when seeking knowledge and learning by studying variations in the reality, including studies of successful examples in the field of interest. This is in line with statements by Lincoln and Guba (1985) regarding a purposeful selection instead of using the traditional approach of finding a selection of cases that is a statistical representative of a population.

\subsection{Data collection}

Starting off with a precise research question and most often a hypothesis, as suggested by Yin (2003), creates a behavior where the researcher sets out to look for what he or she thinks is "out there". An alternative to the previously defined research question is proposed by Löwy (1992), who discusses the importance of loose concepts: a tentative area to study. She argues that loose "boundary" concepts play an important role in the construction of scientific knowledge and in the growth of a discipline. To initiate a research study with a loose concept of interest makes it possible for the research question to emerge and evolve during the research process.

The question that guided the interviews in the case study was "What are the factors that have generated the success of Nacka's education system, in your opinion?" Throughout the interviews, themes and ideas evolved that were confirmed or dismissed in later interviews.

Interviews were held with both with local principals of both private and public schools and employees at the central administration. The Director of Education suggested names and sent the invitations to the interviewees. The result was eight interviews: three principals (two of private schools and one of a public school), the Head of Public Schools, three employees in the central administration of the education system and the Director of Culture and Education responsible for all the schools in Nacka. Each interview lasted for one to two hours and was documented with handwritten notes.

\subsection{Data analysis}

When all the interviews had been performed, the material was grouped in categories in an affinity diagram. The result was four categories representing the principles for managing the education system in Nacka (see Figure 2).

The next step in the case study was an interactive seminar with the respondents where the results of the analysis were presented together with the frame of reference of CAS. The purpose of the seminar was to verify the results of the analysis and to make a further analysis together. Larsson (2006) claims that the involvement of participants in the interactive analysis creates better theories - leading to new insights, unexpected explanations, an innovative perspective and new concepts and theories. The respondents confirmed the four principles during the seminar and signed off on the findings. The results presented in the case description below represent the analysis including the interactive seminar.

As stated earlier, the task of the researcher is twofold: to contribute to science and to help solve practical problems (Gummesson, 2005). The result of the case study has been spread across the education system in Nacka through several seminars, where the presentation of the material had been requested. 


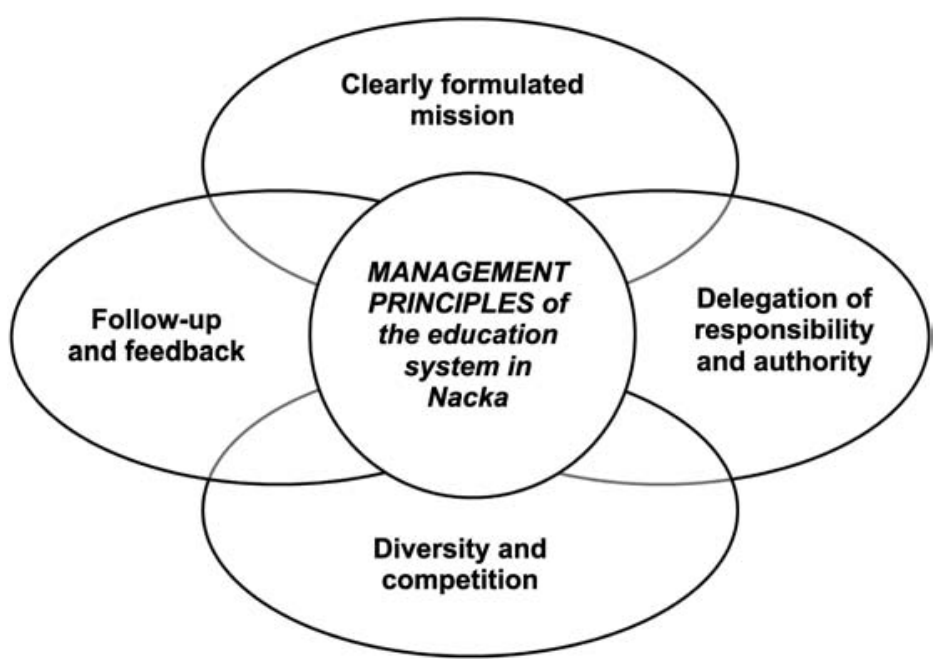

Complex
adaptive systems

489

Figure 2.

Management principles of the education system in

Nacka

\section{Case description of the education system of Nacka municipality}

Nacka is a municipality with 85,000 inhabitants just outside Stockholm, Sweden. The municipality is responsible for schools, childcare, social services, libraries, parks, environmental, health and safety issues, planning for housing and workplaces etc. The study covers the education system with about 17,000 pupils from pre-school to upper secondary school (school year 12). The education is provided through both private schools (31 percent) and public schools (69 percent).

In 2008, the education system in Nacka received an evaluation from the Swedish National Agency for Education, stating that the results were exemplary in schools and that the knowledge level among the pupils was above the average in the country.

In Nacka, each pupil (or the parents of under-aged children) has a choice of which school to attend, independent of geography. All the schools are financed by public funding that is distributed through an education check for each pupil, with equal amounts for all. So, the more pupils that choose a school, the more funding. If the pupil switches school, the funding follows. The purpose of the customer choice system is to offer the municipality's residents freedom of choice and direct influence over these services. Decisions on how the services are designed are taken by the providers of the services: the schools in this case.

The roles in the education system are, in brief: pupils, teachers, principals, central administration and politicians. The teachers are employed by their school principal. According to a majority of the respondents, teachers in Nacka are relatively well paid, sufficient resources are put into competence development and the turn-over rate is low in comparison with other municipalities. The principals are employed either by the Head of Public Schools in Nacka or by any of the organizations that run the private schools in Nacka. They have their responsibility delegated from the politicians and are fully responsible for their schools. The turn-over rate is very low among the principals in Nacka compared with other education systems.

The central administration of the education system is responsible for managing the overall educational system and exercising public authority. It is run by the Director of 
TLO

16,6

490
Culture and Education, the Head of the department and several employees. They are responsible for serving politicians with data for decision-making, for managing the education system through follow-up systems, customer surveys, supporting individual schools on request and providing parents and pupils with information about the schools.

The politicians are elected by local voters every four years and decide on objectives, charges, budgets and taxes. The education system is governed by the Education Committee responsible for goals, ambitions and priorities. It is expressed in the organization that the politicians set the vision and tone and then stay back and leave the operations to the professionals.

Nacka has chosen to work with several different forms of governance, employing a core value, vision, objectives and budgetary frameworks. Based on these, the municipality also operates in line with the guiding principles of:

- separation of finance and production;

- competition through consumer choice or competitive tendering;

- competitive neutrality; and

- delegation of responsibility and authority to the lowest qualified level.

The quality assessment system is an important tool; the schools are continuously evaluated and compared. On a yearly basis, all the schools write a quality report including their results and planned improvements. A customer satisfaction survey is performed each year, with a response rate of 89 percent in 2009. Nacka is part of a partnership between municipalities in the Stockholm area where the schools are assessed in peer reviews by teachers and principals from other schools. Each school is observed about every third year and the observations and feedback are all made public. The pupil results in national tests and grades are all collected and displayed.

All the results are transparent and public, displayed in printed information material to the families and on the web in a search engine enabling the comparison of selected schools based on different variables.

The management principles of the education system in Nacka that evolved in the analysis are described in Figure 2. Each of the principles identified is described in the following sections.

\subsection{Clearly formulated mission}

All the respondents state that the politicians and central administrators govern through visions and objectives, and not by becoming involved in the details of the operations. This is seen all the way down to the principals, who state their freedom to run the schools on their own. One of the administrators describes it as "no guidelines or telling the schools what to do - instead we try to create a system that favors certain behaviors". The roles seem clear between the politicians, central administration and principals.

Several of the respondents emphasize the impact of the rhetoric within the administration of education, and the consistence in the message that is communicated. Respondents, both within the administration and in the schools, describe the competitive spirit of the municipality: to be the first to try, to be the best and to compare results continuously with other municipalities. The stated confidence in the schools, principals, teachers and pupils is appreciated throughout the education system. 
4.2. Delegation of responsibility and authority

One of the governing principles in the municipality of Nacka is the delegation of responsibility and authority to the lowest level possible. This is acknowledged in the interviews, and is articulated by both employees in the administration and the principals.

The feeling of responsibility creates creativity and will to change. (Principal, public school)

The intended core value is described as "Confidence in and respect for people's knowledge and their own capacities - and their willingness to shoulder responsibility". All the respondents refer to this as one of the reasons for the strong delegation. Several of the respondents describe the thorough recruitment of managers throughout the education system, both centrally and locally, as one of the reasons for keeping the core value alive.

To be able to have a strong delegation of responsibility, there is a need for a strong follow-up system; in Nacka, it is the quality assessment system. This is explained as enabling the politicians and central administration to delegate to the degree that they do.

\subsection{Diversity and competition}

The competition is described as enabling the decentralization and delegation of responsibility and authority, but also as a result of the customer focus in the form of the customer choice model. Of the compensation to the schools, 98 percent is distributed through the customer choice system; all the schools are treated equally and this is described as creating natural competition between schools. The customer choice system is set up using the principle of supply and demand. About 95 percent of the pupils should be able to attend their first-hand choice of school. The result in 2007 was 93 percent. Of the families, 98 percent use their right to choose a school, and the remainders are placed in schools based on geography.

The principals describe the education system in Nacka as a tough market to compete on. The parents and pupils use their ability to choose and move if they are not satisfied with the school. In this way, the customer choice system is self-decontaminating.

The principals describe the pressure from the parents and pupils as constructive. If a family has complaints, the principal is forced to deal with the issue, and if a solution is not reached, the school loses the pupil.

The diversity is reached by allowing any school to open in Nacka that fulfills some basic requirements. All pedagogical ideas are welcome and it is up to each school to attract pupils. The ideas that bring about good results survive. Neither the politicians nor the central administration are involved with the sizes of the classes, the material used or how the budget is planned. They rely on the parents and pupils to choose and stay in the schools that work and to move if they do not deliver good results.

\subsection{Follow-up and feedback}

It is described in the interviews how the politicians govern through setting objectives for which the central administration finds measures to follow up the results. The Director of Culture and Education explains it as exposing deviations, both those

\section{Complex adaptive systems}


TLO

16,6

492

performing above the rest and those with poor performance. None of the management principles focuses on how the schools go about solving the challenges, and which approaches and tools are used; the focus is on the result:

We govern through what is measured. There is much more governing happening than is visible. (Employee, central administration)

What is achieved must stand comparison. (Head of Public Schools)

The measurement is a way to find what is working and not. It increases our professionalism and we have to deal with the things not working. (Principal, public school)

The opinions differed a little between the respondents on the area of measurements. Some argued the importance of just measuring the critical things, that the measurements must be focused on the pupils' needs and that there is too much measurement going on. At the same time, several respondents stated that the strong delegation of responsibility demands a strong follow-up system, that the follow-up allows for the schools to track the results of their efforts and that the measurements build awareness of important areas and result in improvements.

On the question of what happens if a school does not want to share its results, all the respondents agree. Then, the "rows" in the comparison material on the web and in written material are blank - and the parents and pupils base their decisions on the material available.

\subsection{Learning and improvement}

The central administration only has the authority to close pre-schools; the rest of the schools are governed by the Swedish National Agency for Education. When the results in a school do not meet the desired objectives, it is described how the central administration makes disturbances. A disturbance is explained as an intervention, often in the form of a visit from the Director of Culture and Education asking questions like "how will you tackle this?" and "do you need any support from us?" A lighter intervention that is described consists of inspirational speakers at conferences twice a year "to shed light on important issues".

The views on the common areas for learning and improvement between schools, such as the conferences, differ. The respondents in the central administration share a positive picture that the schools are cooperating and sharing ideas for improvements. The view among the principals is the opposite. They describe the management principle of competition as overruling any attempts for cooperation:

It is in the nature of the competition that it is difficult to cooperate. I would never share a good idea with another principal, especially not a principal with a school in my neighborhood. (Principal, public school)

There also seems to be a tension between the public and the private schools. The public schools cooperate under the Head of Public Schools but the private schools do not have any forum for cooperation except the opportunities set up by the central administration for all schools.

When asked about the challenges to come, the respondents describe the increasing demands from parents and the decreasing number of pupils in the years to follow. Other challenges that are mentioned are: the increased need to search for new ideas and 
inputs, to improve the collaboration between schools, to increase the ability to use the data that the assessment systems generate and to keep the competence level high among all the employees in the schools.

\section{Complex adaptive systems}

\subsection{Reflections on the results}

With a background in quality management, I was initially looking for tools and methodologies as an answer to why the education system in Nacka had achieved its success. After three interviews, I started explicitly asking for tools and approaches and had the early findings confirmed: none of the interviewees talked about traditional tools and approaches when explaining their view on why Nacka had reached their results. Each school, or organization of schools, had approaches and tools for improvement and learning in their own organization. However, the politicians and the central administration did not use tools and approaches to manage the education system as a whole.

When asked about the absence of tools and approaches, the Director of Culture and Education replied "if you understand your task, are normally capable and curious, you do not need centrally developed tools, you will come up with your own solutions to tackle problems that you observe". At the interactive seminar, the reactions to this finding were quite strong since several of the respondents have a background in the quality management movement. However, the discussions led to agreement:

We have tools and approaches, but they are not mandatory and we do not manage through tools and approaches. (Head of Public Schools)

Instead, when managing the education system, the politicians and central administration in Nacka focus on the desired results and have a strong follow-up system. This enables the schools to choose approaches that fit their organization and management ideas, while at the same time allowing the politicians and central administration to define and manage the desired direction and development of the overall education system.

\section{A tentative model for system management}

In this section, a tentative model for managing organizations as CAS combining the frame of reference and the case study is presented. The model includes a suggestion for a metaphor of organizations as CAS, components of and approaches to managing organizations as CAS - system management.

In the introduction, the importance of metaphors and images was emphasized. Figure 3 shows a suggestion for a metaphor of an organization as a CAS containing:

- the system holder;

- the interdependent agents; and

- the system boundary.

The symbol of the CAS is reoccurring; every CAS contains other CAS, each with a system holder, interactive agents and boundaries. The CAS is also surrounded by other CAS. In Nacka, each school is a CAS within the education system. 


\section{TLO \\ 16,6}

\section{4}

Figure 3.

A metaphor of an organization as a CAS

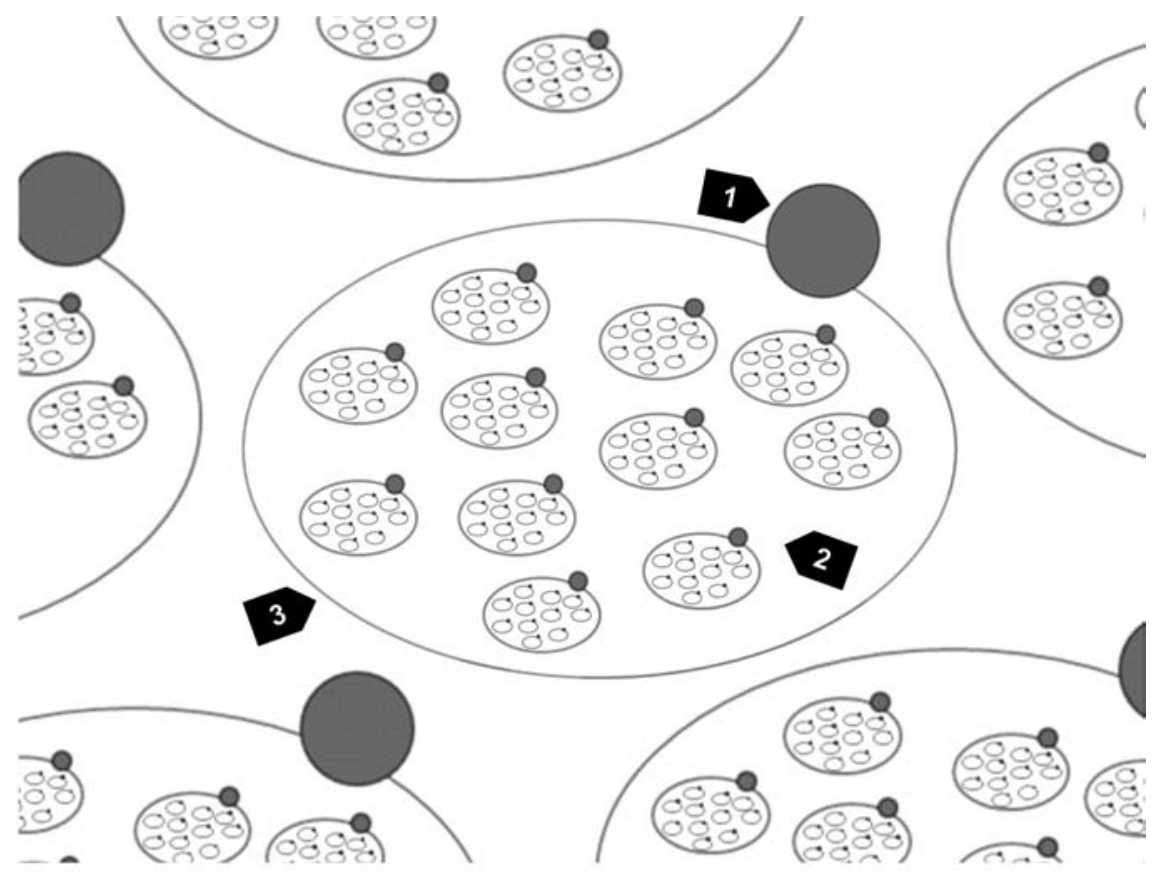

Notes: 1 : the system holder; 2 : the interdependent agents; 3 : the system boundary

\subsection{System holder}

The task of the system holder is to manage the CAS. This task exists in all CAS that do not have a totally flat anarchical type of governance. Based on the analysis of the results, it is suggested that the tasks of the system holder when managing the CAS are:

- visioning and setting simple rules;

- building and maintaining follow-up and feedback systems; and

- creating attractors.

In Nacka, the system holder (politicians, the Director of Culture and Education and her staff at the central administration) uses the idea of visioning and simple rules within the principle of a clearly formulated mission and the way they do not get involved in details or how the schools set about solving their mission. The education system in Nacka is governed by the four guiding principles presented in the case description and these can be interpreted as simple rules with the purpose of guiding all the work in the municipality.

Systems for follow-up and feedback can be used to enable learning, self-organization and emergence. The better the feedback is, the better the possibilities and opportunities for reflection and reaction among the agents in the CAS. In Nacka, the quality assessment system strengthens the opportunities for learning and improvement. 
According to the frame of reference, a system holder cannot enforce a CAS of agents to move in a certain direction, but one can build attraction. In Nacka, the transparency with which the results were displayed can be seen as one way of creating attraction. To

\section{Complex adaptive systems} have good results in the comparisons is attractive for the schools because that attracts pupils and thereby funding.

A challenge for a system holder is to keep up the tension level and the dynamics in a CAS. According to the frame of reference, tension is needed for the CAS to stay flexible and innovative. Nacka uses the customer choice to maintain tension among the schools through competition for pupils. Another way is the disturbances and interventions described. However, one could question whether the competition is enough to keep the schools "on their toes" when they have all reached a fairly good level of quality. In an education system with equally performing schools, what triggers agents to drive innovation when they are already good enough to keep up the inflow of new customers?

\subsection{Interdependent agents}

CAS are made up of interdependent agents, themselves CAS. The control of the CAS is to varying degrees distributed between the system holder and the agents. In Nacka, the delegation of responsibility and authority enables the distribution of control to the principals in the independent schools. Detailed instructions are replaced by visions and simple rules.

In Nacka, relationships between agents are defined by competition as a result of the customer choice. The competitive environment triggers the development of each school, but not the CAS as a whole. The competition may limit the possibilities of co-evolution and emergence between agents as the principals testify that they do not share ideas with other principals and do not cooperate.

It is a challenge for the system holder to make use of the form of organizing as a CAS instead of in hierarchies, processes or supply chains, and to take advantage of the interdependencies between agents and the distribution of control that enables development and innovations with little or no intervention by the system holder. One way of approaching this could be to create areas for collaboration, experimentation and reflection among agents, using attractors to gather agents, diversity among agents to create tension between ideas and chunking for the development and spread of innovations.

\subsection{System boundaries}

The metaphor of the cell membrane can be used when discussing the system boundary. It is a clear boundary while at the same time allowing the transportation of information, fluids and waste. The thickness of the membrane, the degree of definition, depends on the open or closed profile of the CAS. If the participation is open to everyone, the boundary is very vague. In Nacka, the education system is open for everyone to establish a school. Still, a school needs to be authorized by the central administration - the system holder. Therefore, the boundary of the education system is rather clear.

\section{Summary and conclusions}

Our ideas about how to manage organizations is formed and limited by our mental models and metaphors and these are often dominated by the functional organizational 
TLO

16,6

496 chart. There is a need for development of metaphors and language for managing of the new forms of organizing that are evolving, for example value networks. The paper presents possibilities of using the knowledge of CAS in developing the management of organizations. The frame of reference is based on a literature review of the area and a classification is suggested and described as; properties of CAS and approaches for managing CAS.

With the purpose of contributing to the empirical body of knowledge of organizing and management, a descriptive case study of the education system of Nacka municipality, an organization using unconventional management principles to govern, is presented. An inductive and interactive analysis is used to identify the management principles used: a clearly formulated mission, delegation of responsibility and authority, diversity and competition, and follow-up and feedback, see Figure 2.

As a result of analyzing the frame of reference and the case study, a tentative, conceptual model for managing organizations as CAS - system management - is presented, see Figure 3. The model includes a metaphor of an organization as a system, components of and approaches to management and is a contribution to the ongoing discussion about managing organizations as CAS.

A suggestion for future research is to explore further the possibilities of using CAS as a metaphor for organizations and develop approaches to managing organizations as CAS. There is a need for further research on how to drive innovation and improvement in a CAS with distributed control. The challenge of developing approaches for learning and improvement in a CAS is a possible step for the education system in Nacka to take on, to create attractors for collaboration and learning in a system governed by competition.

\section{References}

Ackoff, R.L. (1999), Re-creating the Corporation: A Design of Organizations for the 21st Century, Oxford University Press, New York, NY.

Augustinsson, S. (2006), "Om organiserad komplexitet: integration av organisering, lärande och kunnande" ("About organized complexity: integration of organizing, learning and knowing", doctoral thesis, No. 2006:46, Department of Industrial Production Environment, Luleå University of Technology, Luleå) (in Swedish).

Cilliers, P. (2000), Complexity and Postmodernism. Understanding Complex Systems, Routledge, London.

Cohen, M. (1999), "Commentary on the organizational science special issue on complexity", Organizational Science, Vol. 10 No. 3, pp. 373-6.

Cook, S. (2008), "The contribution revolution: letting volunteers build your business", Harvard Business Review, Vol. 86 No. 10, pp. 60-9.

Deming, E. (1994), The New Economics for Industry, Government, Education, 2nd ed., MIT, Cambridge, MA.

Eurat, M. (2006), "Feedback", Learning in Health and Social Care, Vol. 5 No. 3, pp. 111-18.

Gharajedaghi, J. (1999), Systems Thinking: Managing Chaos and Complexity, Butterworth-Heinemann, Woburn, MA.

Gharajedaghi, J. (2007), "Systems thinking: a case for second-order-learning", The Learning Organization, Vol. 14 No. 6, pp. 473-9. 
Gummesson, E. (2000), Qualitative Methods in Management Research, 2nd ed., Sage Publications, Thousand Oaks, CA.

Gummesson, E. (2005), "Qualitative research in marketing: road-map for a wilderness of complexity and unpredictability", European Journal of Marketing, Vol. 39 No. 3/4, pp. 309-27.

Gummesson, E. (2007), “Case study research and network theory: birds of a feather”, Qualitative Research in Organizations and Management: An International Journal, Vol. 2 No. 3, pp. 226-48.

Gummesson, E. (2008), "Case study research", in Gustavsson, B. (Ed.), The Principles of Knowledge Creation: Research Methods in the Social Sciences, Edward Elgar, Cheltenham, pp. 87-110.

Hamel, G. (2007), The Fututre of Management, Harvard Business Press, Boston, MA.

Hamel, G. (2009), "Moon shots for management”, Harvard Business Review, Vol. 87 No. 2, pp. 91-8.

Kalleberg, R. (1993), "Konstruktiv samhällsvetenskap" ("Constructive social research"), in Holmer, J. and Starrin, B. (Eds), Deltagarorienterad forskning (Participatory Research (in Swedish)), Studentlitteratur, Lund, pp. 27-50 (in Swedish).

Kelly, S. and Allison, M. (1999), The Complexity Advantage: How the Science of Complexity Can Help Your Business Achieve Peak Performance, McGraw-Hill, New York, NY.

Larsson, A.-C. (2006), "Interactive research - methods and conditions for joint analysis", in Nielsen, K.A. and Svensson, L (Eds), Action Research and Interactive Research; Beyond Practice and Theory, Shaker Publishing, Maastricht, pp. 241-58.

Lee, B., Collier, P.M. and Cullen, J. (2007), "Reflections on the use of case studies in the accounting, management and organizational disciplines", Qualitative Research in Organizations and Management: An International Journal, Vol. 2 No. 3, pp. 169-78.

Lincoln, Y. and Guba, E. (1985), Naturalistic Inquiry, Sage Publications, Thousand Oaks, CA.

Lissack, M. (1999), "Complexity: the science, its vocabulary, and its relation to organizations", Emergence, Vol. 1 No. 1, pp. 110-26.

Löwy, I. (1992), "The strength of loose concepts - boundary concepts, federative experimental strategies and disciplinary growth: the case of immunology", History of Science, Vol. 30, pp. 371-96.

Morgan, G. (2006), Images of Organizations, updated ed., Sage Publications, Thousands Oaks, CA.

Ng, P.T. (2009), "Examining the use of new science metaphors in learning organization", The Learning Organization, Vol. 16 No. 2, pp. 168-80.

Palmberg, K. (2009a), "Experiences of implementing process management: a multiple-case study", Business Process Management Journal (forthcoming).

Palmberg, K. (2009b), "Exploring process management: are there any widespread models and definitions?", The TQM Journal, Vol. 21 No. 2, pp. 203-15.

Palmberg, K. (2009c), Complex Adaptive Systems: Properties and Approaches, Luleå University of Technology, Luleå.

Palmberg, K. (2009d), “An alternative case study approach in management research”, in Elg, M. and Andersson Gäre, B. (Eds), Vägval och dilemman in interaktiv forskning (Crossroads and Dilemmas in Interactive Research), Linköping University, Linköping.

Reynolds, C. (2001), "Boids" 6 September, available at www.red3d.com/cwr/boids/ (accessed 20 January 2008). 
TLO

16,6

498

Richardson, K. (2008), "Managing complex organizations: complexity thinking and the art and science of management", Emergence, Vol. 10 No. 2, pp. 13-26.

Sandberg, J. and Targama, A. (2007), Managing Understanding in Organizations, Sage Publications, London.

Senge, P. (1990), The Fifth Discipline: The Art and Practice of the Learning Organization, Century Business, London.

Smith, A. (2005), "Complexity theory for organisational future studies", foresight, Vol. 7 No. 3, pp. 22-30.

Stacey, R. (2003), "Organizations as complex responsive processes of relating", Journal of Innovative Management, Winter 2002/2003, pp. 27-39.

Tapscott, D. and Williams, A. (2006), Wikinomics; How Mass Collaboration Changes Everything, Penguin Group, New York, NY.

Tetenbaum, T. (1998), "Shifting paradigms: from Newton to chaos", Organizational Dynamics, Spring, pp. 21-32.

von Bertalanffy, L. (1968), General Systems Theory, George Braziller, New York, NY.

Weiss, C. (1977), Using Social Research for Public Policy Making, Lexington Books, Lexington, MA.

Weiss, C. (1980), Social Science Research and Decision Making, Columbia University Press, New York, NY.

Weiss, C. (1986), “The many meanings of reseach utilisation”, in Bulmer, M. (Ed.), Social Science \& Social Policy, Allen \& Unwin, London.

Yin, R. (2003), Case Study Research: Design and Methods, 3rd ed., Sage Publications, Thousand Oaks, CA.

Zimmerman, B., Lindberg, C. and Plsek, P. (1998), Edgeware: Insights from Complexity Science for Health Care Leaders, VHA Inc., Irving, TX.

\begin{abstract}
About the author
Klara Palmberg presented her licentiate thesis on "Experiences of process management" in 2005. Since then, she has shared her time between research and management consulting. Her doctoral thesis on "Beyond process management" is planned for August 2009. Within both her research and management consulting practice, she is working with organizations exploring process management and the challenge of complexity - how to manage organizations as complex adaptive systems. She can be contacted at: klara.palmberg@mementor.se
\end{abstract}

To purchase reprints of this article please e-mail: reprints@emeraldinsight.com Or visit our web site for further details: www.emeraldinsight.com/reprints 